\title{
Mental Fatigue and Its Effect on the Performance of the Faculty of Health Staff Using Electroencephalographic Signals
}

\author{
Abbas Mohammadi', ${ }^{1, \text { Behzad Fouladi Dehaghi }}{ }^{1,3}$, Leila Nematpour,,* \\ ${ }^{1}$ Department of Occupational Safety and Health Engineering, Environmental Technologies Research Center, Faculty of \\ Health, Ahvaz Jundishapur University of Medical Sciences, Ahvaz, Iran \\ ${ }^{2}$ Assistant Professor, Department of Occupational Safety and Health Engineering, Faculty of Health, Ahvaz. Jundishapur \\ University of Medical Sciences, Ahvaz, Iran \\ ${ }^{3}$ Associate Professor, Department of Occupational Safety and Health Engineering, Faculty of Health, Ahvaz, Jundishapur \\ University of Medical Sciences, Ahvaz, Iran \\ ${ }^{4}$ MSc in Occupational Health Engineering, Department of Occupational Safety and Health Engineering, Faculty of Health, \\ Ahvaz Jundishapur University of Medical Sciences, Ahvaz, Iran
}

* Corresponding Author: Leila Nematpour, Department of Occupational Safety and Health Engineering, Faculty of Health, Ahvaz.Jundishapur University of Medical Sciences, Ahvaz, Iran. Email: Lnematpour94@gmail.com

Received: $20 / 01 / 2019$ Accepted: 10/03/2019

How to Cite this Article:

Mohammadi A, Fouladi Dehaghi B, Nematpour L. Mental Fatigue and Its Effect on the Performance of the Faculty of Health Staff Using

Electroencephalographic

Signals. J Occup Hyg Eng. 2019;

5(4): 41-49. DOI: 10.29252/ johe.5.4.41

\begin{abstract}
Background and Objective: Mental fatigue usually occurrs as a result of long-term cognitive activities. Mental fatigue could have important effects on the daily lives of healthy people. Therefore, the purpose of this study was to estimate mental fatigue and its impact on staff performance.

Materials and Methods: This descriptive analytic study was performed on 10 staff with a mean age of $36 \pm 6.19$ years. To evaluate the performance of the participants, they were asked to read a text with spelling errors and then correct them. This test was performed in 5 steps of 15 min during which electroencephalography (EEG) was performed. At each step, the Karolinska Sleepiness Scale (KSS) was completed by the staff. The data were analyzed statistically by the repeated measures ANOVA and Pearson correlation coefficient.

Results: According to the results, the brain waves decreased during the experiment, which was indicative of increased mental fatigue. The EEG was recorded as 213.14 \pm 59.98 and $77.68 \pm 21.68$ in the first and last $15 \mathrm{~min}$, respectively. In addition, the participants were reported their fatigue by KSS, based on which the performance of the participants was shown to decrease from $27.3 \pm 4.53$ to $17.5 \pm 5.19$.

Conclusion: The EEG facilitates the investigation of mental fatigue over different periods of time. As the results indicated, mental fatigue caused by long-term cognitive activities could result in the reduction of the accuracy, focus, and consciousness of the staff. Finally, increased mental fatigue led to the recution of the quality of individuals' performance.
\end{abstract}

Keywords: Electroencephalography; Karolinska Sleepiness Scale; Mental fatigue; Performance 


\section{بررسى خستّى ذهنى و تأثير آن بر عملكرد كار كنان دانشكده بهداشت با استفاده از امواج الكتروانسفالو ترافى}

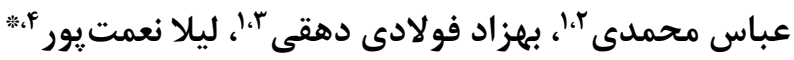

' مركز تحقيقات فناورىهاى زيست محيطى، دانشكاه علوم يزشكى جندى شايور اهواز، اهواز، ايران

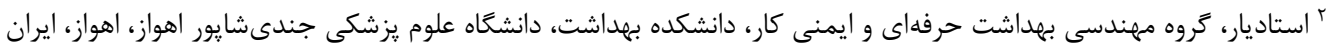

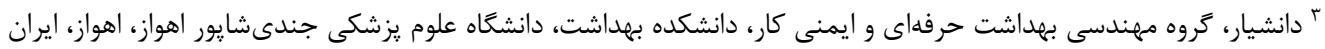

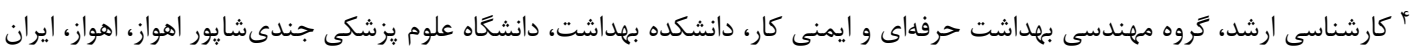
* نويسنده مسئول: ليلا نعمت يور، كروه مهندسى بهداشت حرفهاى و ايمنى كار، دانشكده بهداشت، دانشگاه علوم يزشكى جندى إيور اهواز، اهواز، ايران. ايميل: Lnematpour94@gmail.com

\section{קكيده}

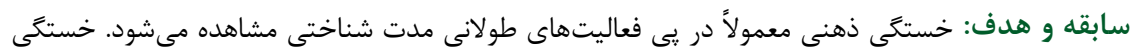

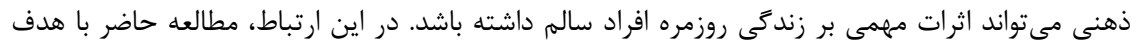

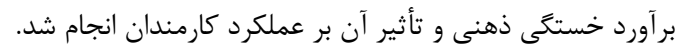

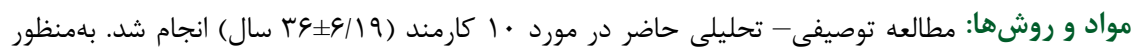

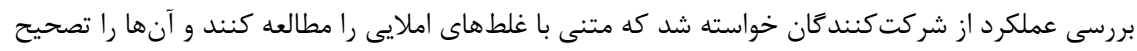

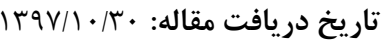

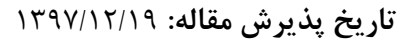
تمامى حقوق نشر براى دانشكاه علوم يزشكى همدان محفوظ است.

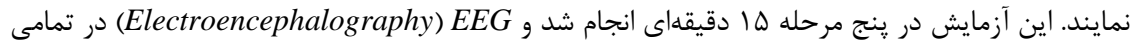

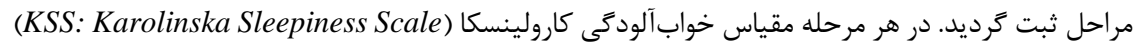

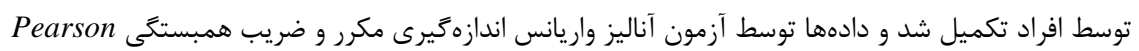
مورد تجزيه و تحليل آمارى قرار كرفتند.

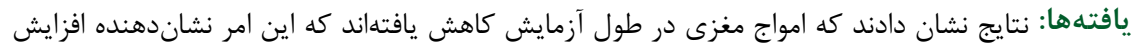

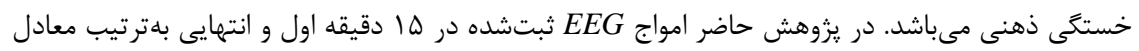

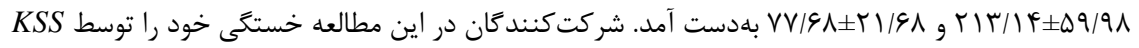

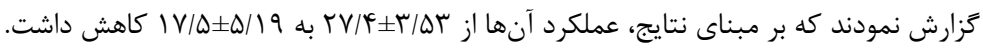
نتيجه كَيرى: در اين يزوهش نشان داده شد كه با استفاده از

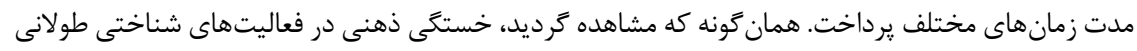

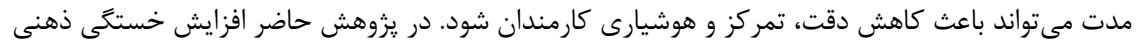
منجر به كاهش عملكرد و كيفيت فعاليت افراد كرديد.

وازَّان كليدى: الكتروانسفالو گرافى؛ خستخى ذهنى؛ عملكرد؛ مقياس خوابآلودىى كارولينسكا

[r][]. مطالعات نشان مىدهند كه با بالارفتن سطح وظيفه،

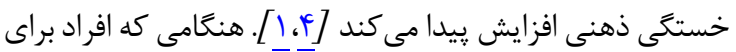

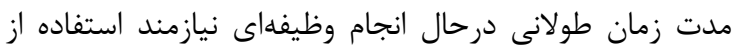
عملكردهاى شناختى هستند، اغلب خستكى ذهنى ذهنى رانى را تجربه

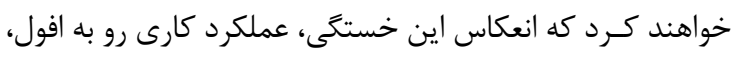

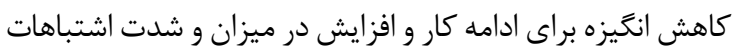

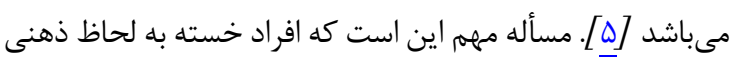

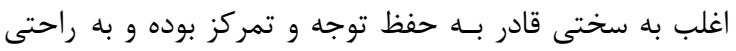

خستكى ذهنى عبارت است از خستهشدن جسم يا روح كه

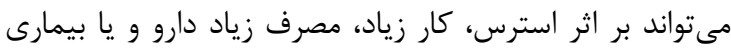

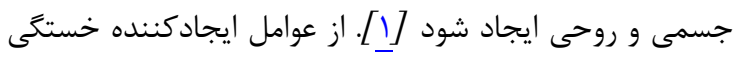

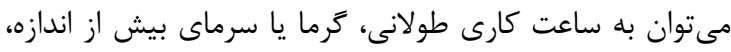

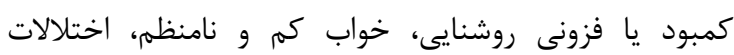
فيزيولوزيك و نورولوزيك، فعاليت يكنواخت، مشكلات اجتماعى رئى

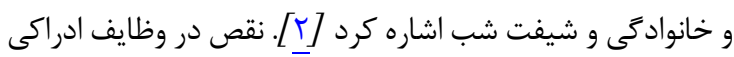
و شناختى منجر به اختلال در عملكرد و كارايى فرد مى لىرد 
رو، در مطالعه حاضر تلاش شده است تا از يك سو خستخى ذهنى

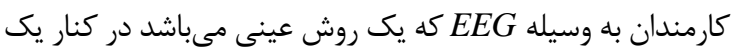
روش ذهنى مورد بررسى قرار گيرد و از سوى ديخر بتوان عملكرد افراد را به مرور زمان مورد ارزيابى قرار داد.

\section{مواد و روشها}

در مطالعه توصيفى- تحليلى حاضر • ا كارمند دانشكده

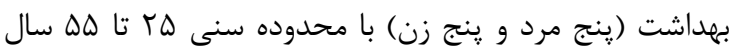

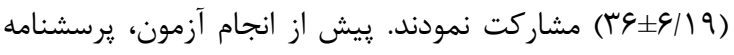

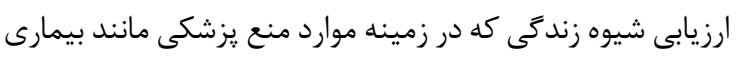

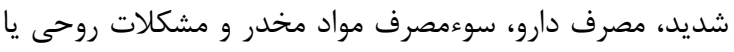

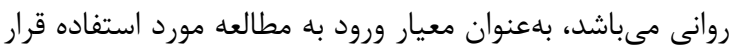

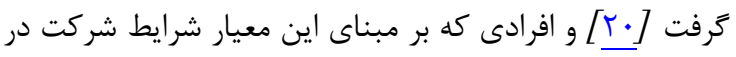

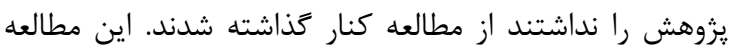

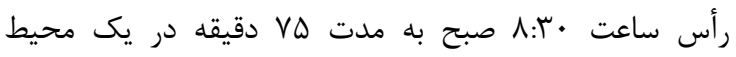

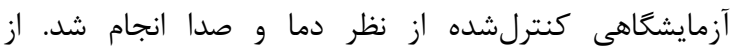
شركت كنند

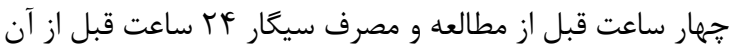

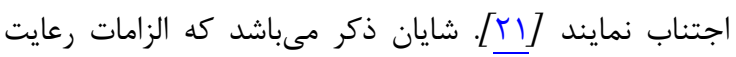

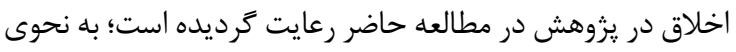

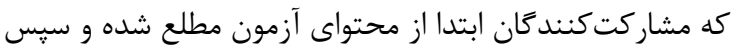
بلهور داوطلبانه در مطالعه شركت نمودند.

\section{اندازمكيرى فيزيولوزيكى}

در اين يزوهش از دستخاه يرتابل NeXus-4 ساخت كميانى

مايند مديا (Mind Media B.V. Company, Netherlands)

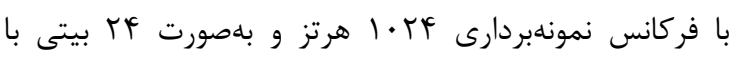

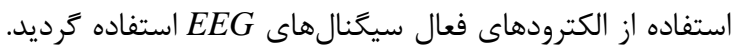

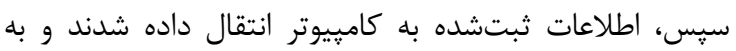

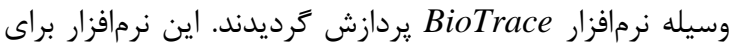
يردازش سيخنال EEG و يا ديخر دادههاى الكتروفيزيولوزيكى و

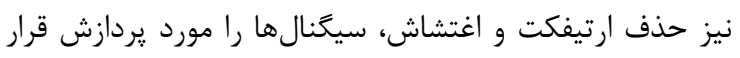

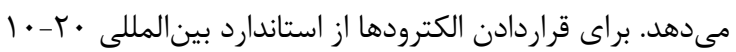

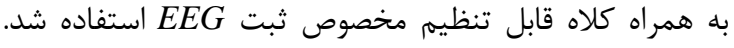

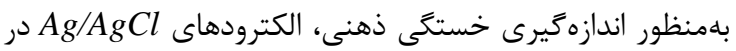
نقاط به آمادهسازى يوست) روى سر قرار گرفتند. مطابق با دستور العمل

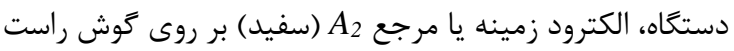
قرار داده شد [Yr].

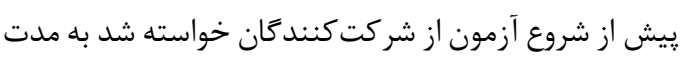

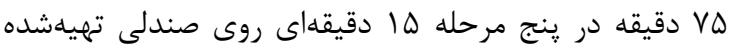
براى انجام آزمون مستقر شوند تا كلاه براساس سايز سر درى
يريشان و حواسيرت مىشوند كه اين امر بيانكر اثرات خستخى

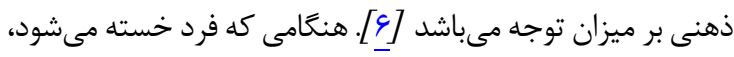
مشكلاتش در حفظ توجه و تمركز بر كار افزايش مىيابد. در فرايند مئد

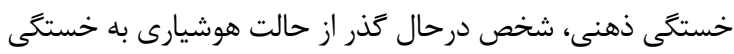

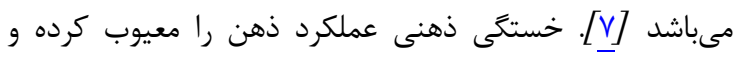

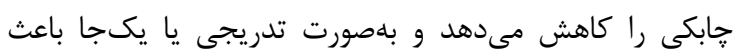

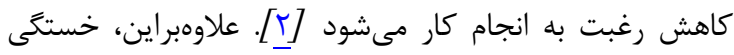

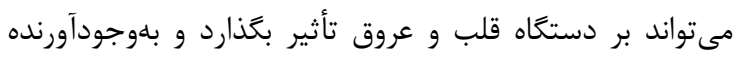
بيمارىهاى روانى، كندى ذهن، بى خوابى، ضعف، كاهش حافظه،

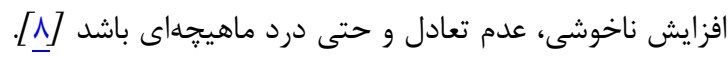

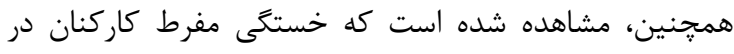

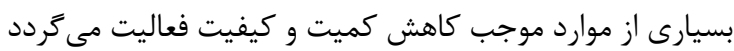

معيارهاى مختلفى براى سنجش خستخى ذهنى مطرح

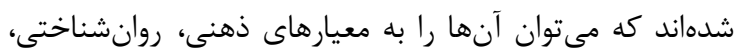

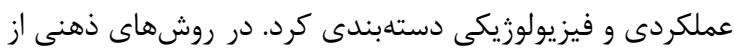

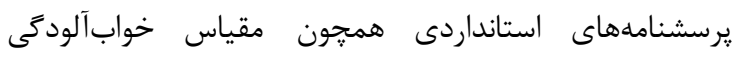
كرولينسكا (KSS) استفاده مىشود [11) مقياس به وسيله متغيرهاى KEG توسط Kaida انجام شده است كه نشاندهنده اعتبار بالايى در اندازمكيرى سطح هوشيارى

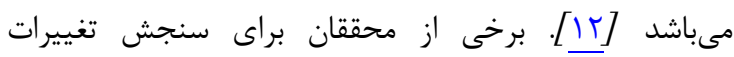

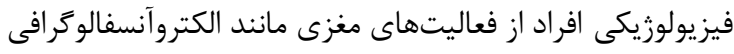
به (EEG)

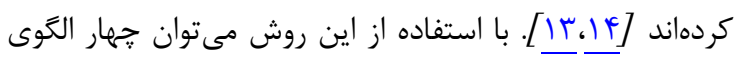

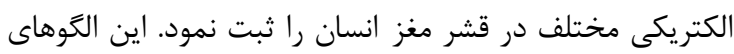

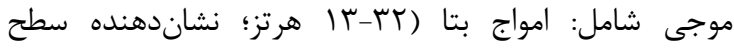

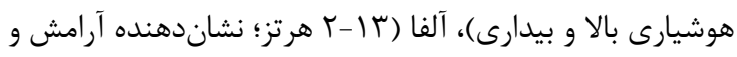

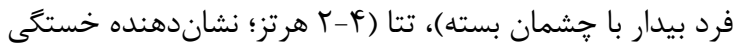

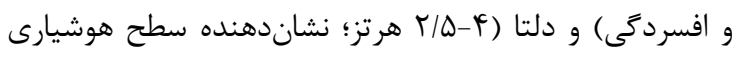

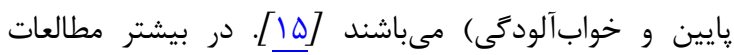

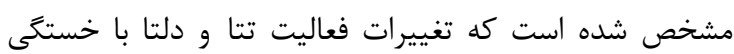

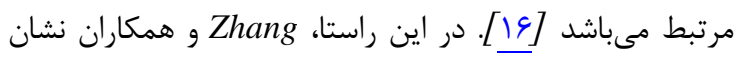

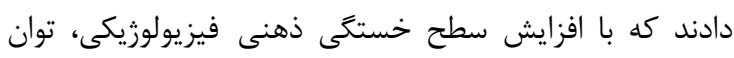

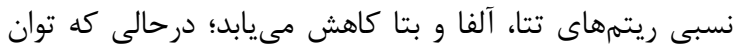

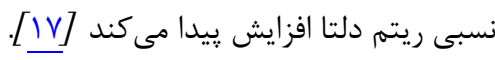
خستخى يكى از مهمترين مسائل در محيطهاى كارى مى بـاشد

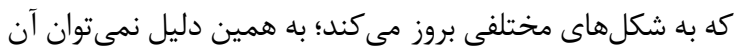

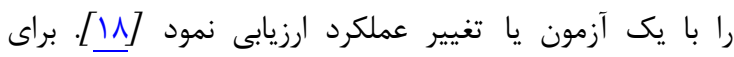

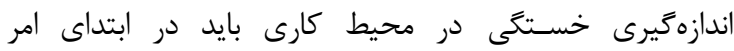

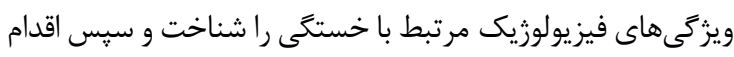

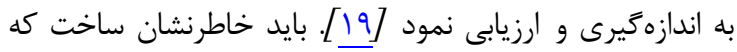

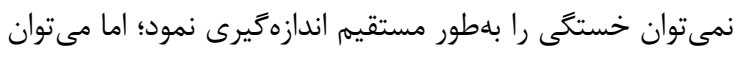

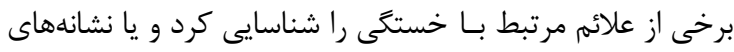

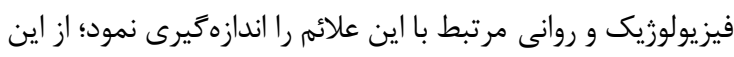


شد و نسبتهاى F- جندمتغيره قابل مقايسه با استفاده از درجه تك آزادى به وسيله نرمافزار 22 SPSS تجزيه كردين

بافته.

در اين مطالعه يافتهها به جندين بخش تقسيم شدهاند كه

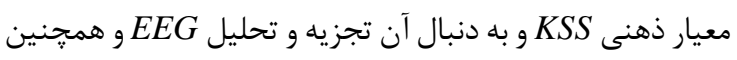

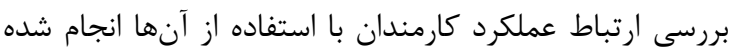

\section{مقياس خودكز/رشدهى}

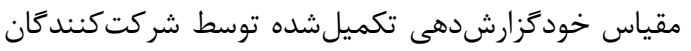
در شكل I ارائه شده است. شركت كنيند خزارش نمودند كه وقتى كار تمام مىشود، احساس خستخى

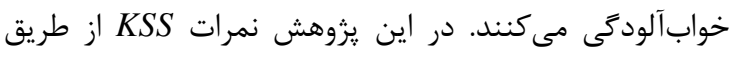

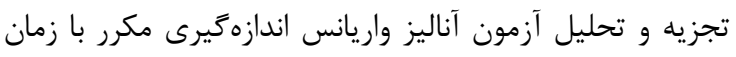
اندازهيرى در هر مرحله بررسى شدند. ميانكين و انحراف معيار

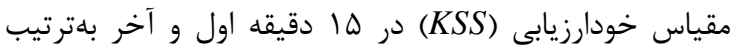

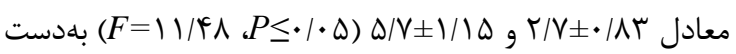

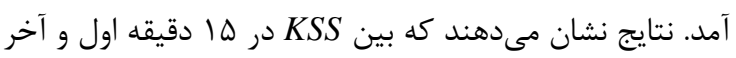
اختلاف معنادارى وجود دارد.

\section{دقت و عملكرد}

در مرحله اول شركت كنند

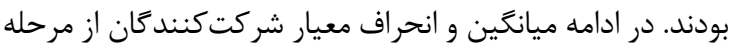

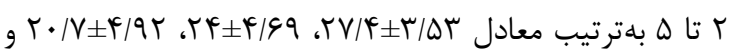
IV/DIه/I 9

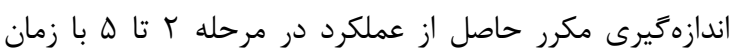

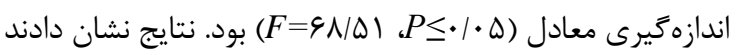

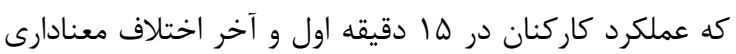

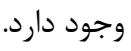

\section{آناليز امواج EEG}

تغييرات قدرت آلفا، بتا و تتا در قسمت فرونتال و ياريتال در آنال

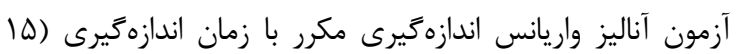

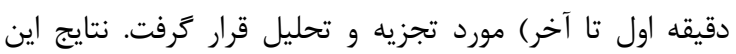

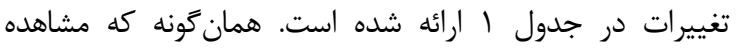

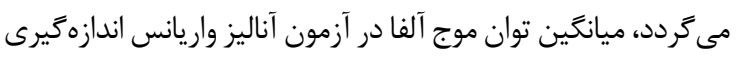

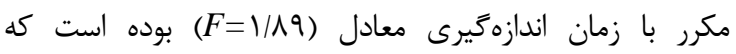

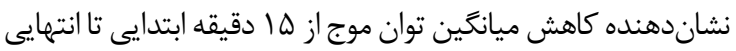

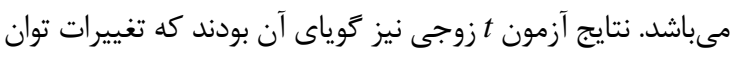

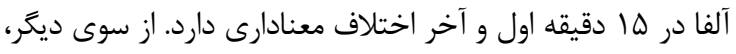

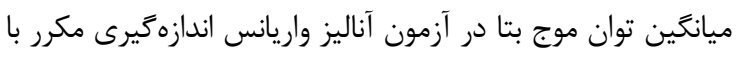

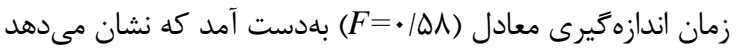

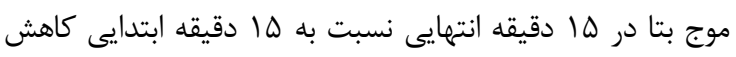

شركت كنند گان و مطابق با دستور العمل سازنده تنظيم گَردد. در

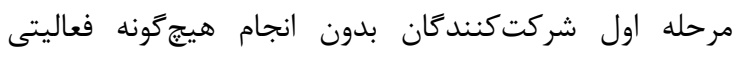

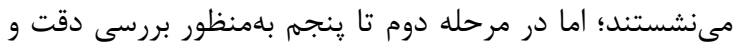

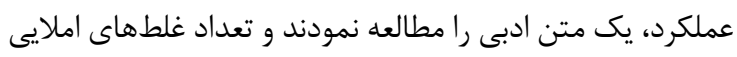
موجود در متن را مشخص كردند؛ بهطور همزمان فعاليت امواج

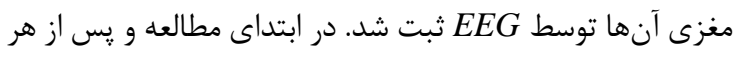

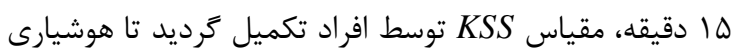

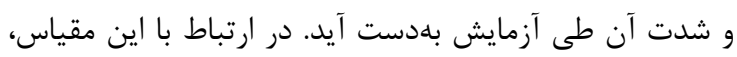

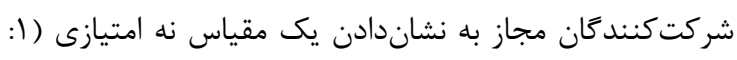

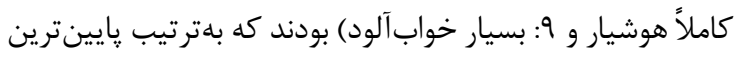

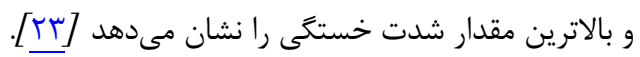

آناليز EEG

يس از ثبت سيخَنال، مرحله اساسى براى استخراج اطلاعات

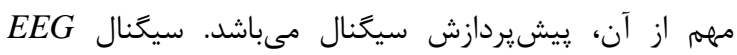

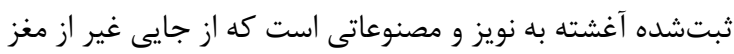

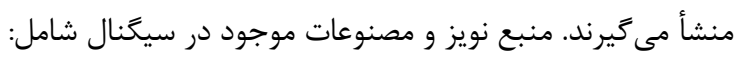

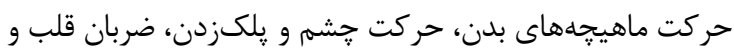

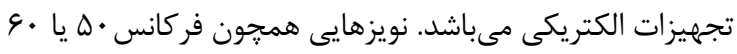

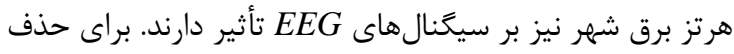
اثر نويز برق شهر عموماً سعى ميىشود كه وسايل ثبت تا حد امكان

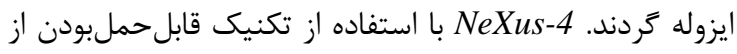
كابلهاى يوششدادهشده با كربن استفاده مى كند كه هر كابل از

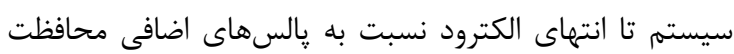

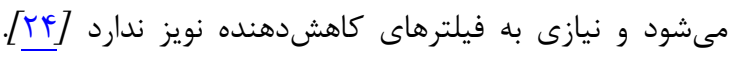

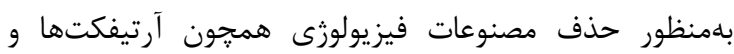

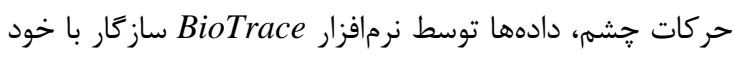

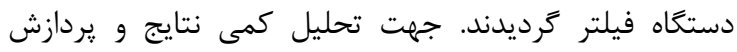

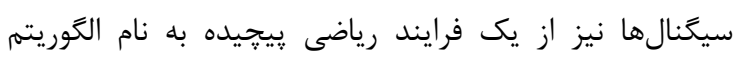

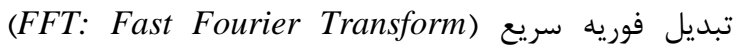
استفاده مىشود. شايان ذكر است كه تمام دادهها توسط نرمافزار BioTrace

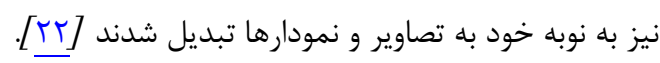

\section{آناليز دادهها}

در اين يزوهش بهمنظور بررسى نرمالبودن توزيع دادهها از

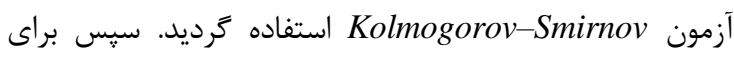
بررسى اثرات زمان بر متغيرهاى مختلف (مانند عملكرد و

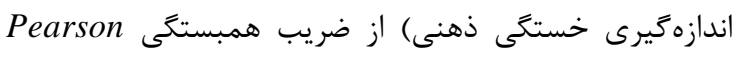

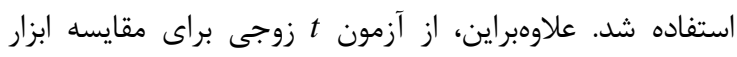

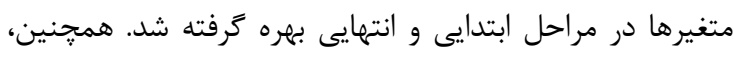

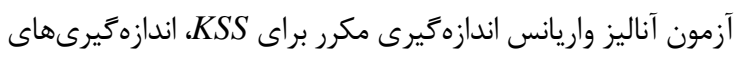

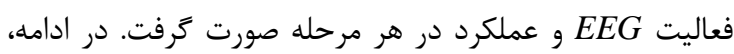
تجزيه و تحليل جندمتغيره واريانس براى زمان و و عملكرد انجام 
در ها دقيقه اول و آخر اختلاف معنادارى داشتهاند.

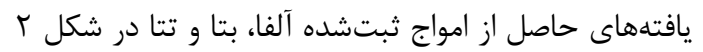

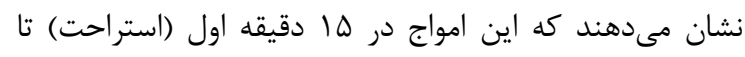

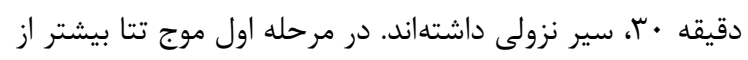

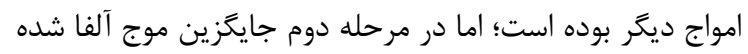

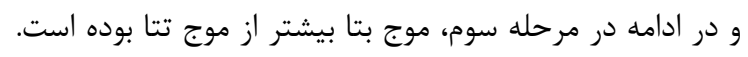

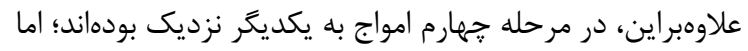

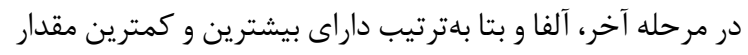
بودهاند؛ اما در مجموع تمامى امواج سير نزولى داشتهاند.

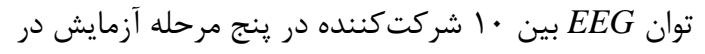

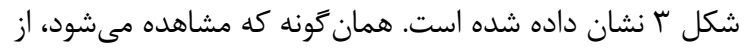

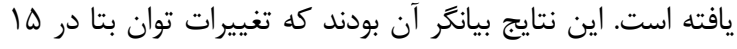

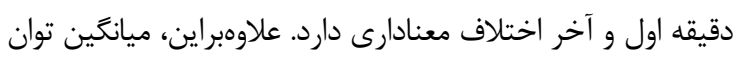

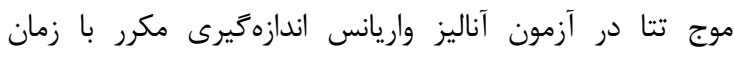

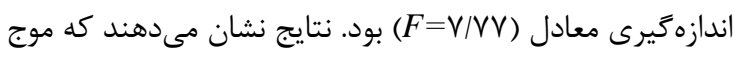
بتا داراى تغييرات جزئى در مرحله انتهايى نسبت به مرحله

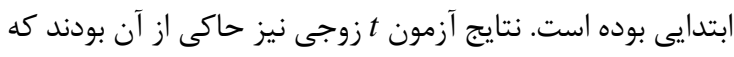

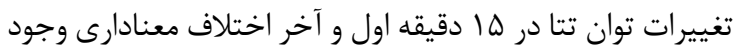
دارد. در ادامه، تغييرات فعاليت EEG در آزمون آنسير آناليز واريانس

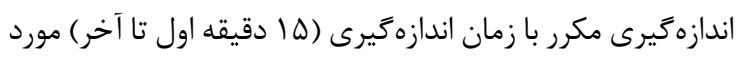
تجزيه و تحليل قرار گرفت كه بر مبناى نتايج، متوسط توان

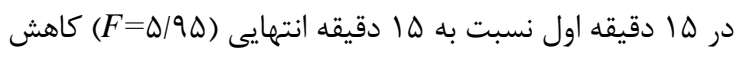

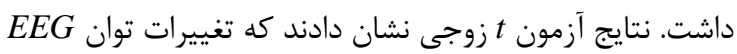

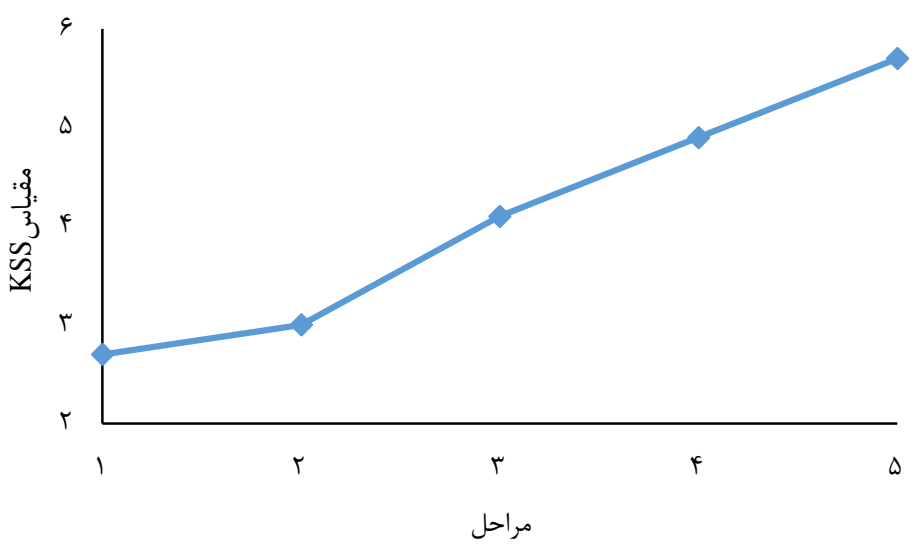

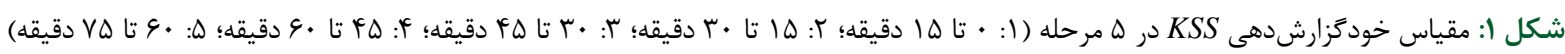

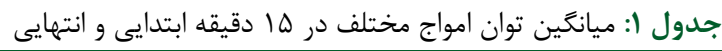

\begin{tabular}{|c|c|c|c|}
\hline معنادارى سطح & $\begin{array}{c}\text { ميانغين توان موج (ميكرو ولت مربع بر هرتز) } \\
\text { ها دقيقه انتهايیى }\end{array}$ & $\begin{array}{c}\text { ميانگين توان موج (ميكرو ولت مربع بر هرتز) } \\
\text { ها دقيقه ابتدايىى }\end{array}$ & هار امتر \\
\hline$\cdot / \cdot r$ & $\Lambda / \Delta H \pm \Delta / r \varepsilon$ & $\mid r / \Delta \Lambda \pm 9 / 9 \Lambda$ & آلفا \\
\hline$\cdot / \cdot r$ & $G / I \pm r / r \Lambda$ & $G / F \pm r / \Delta \Delta$ & بتا \\
\hline $.1 \cdot 4$ & $V / r \pm \Psi / r \Lambda$ & $\mid F / \Lambda V \pm q / \varepsilon \Delta$ & تتا \\
\hline$\cdot 1 \cdot \Delta$ & $V \vee / 9 \Lambda \pm r \mid / 9 \Lambda$ & $r / r / \mid F \pm \Delta q / 9 \Lambda$ & $E E G$ \\
\hline
\end{tabular}

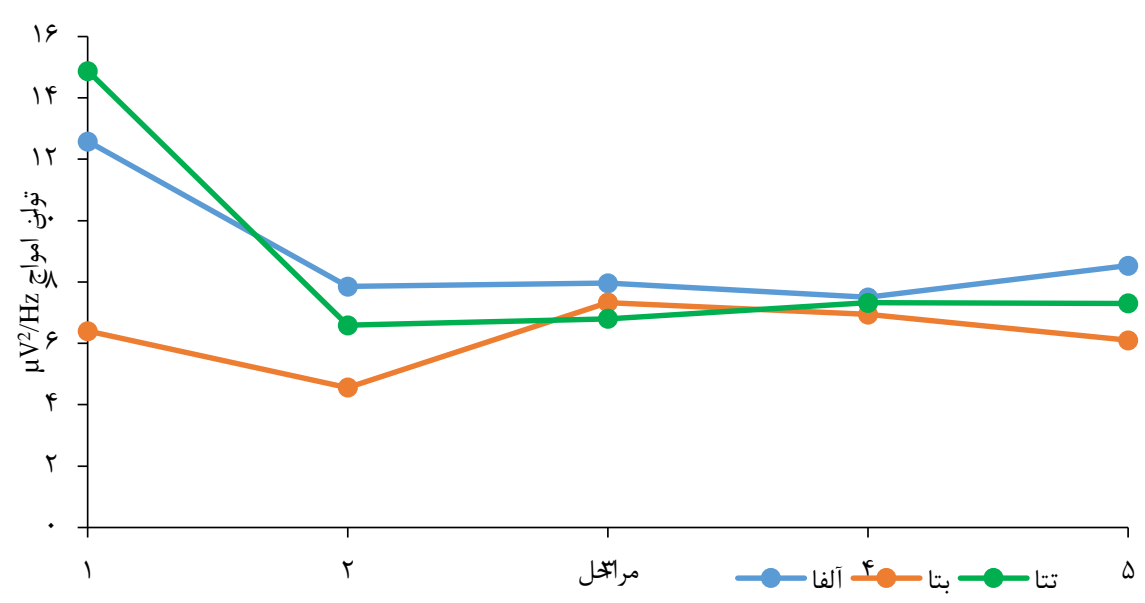




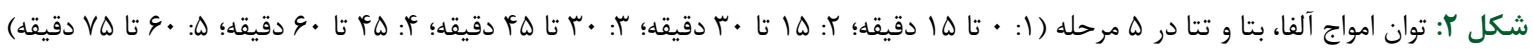
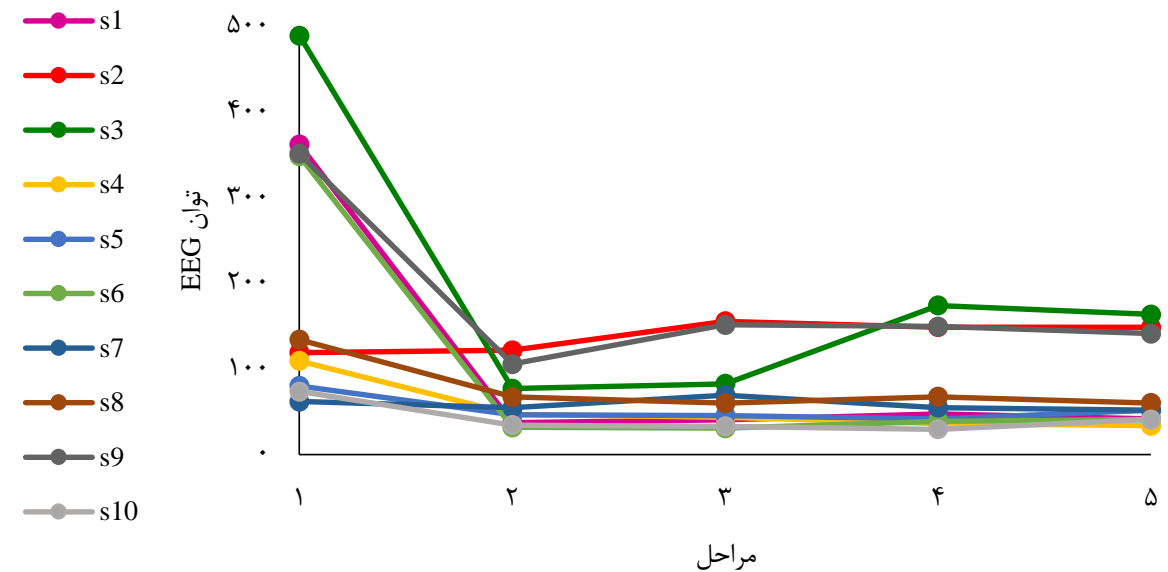

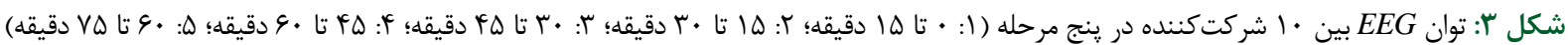

است. اين كاهش در عملكرد به همراه افزايش خستكى به وسيله مقياس خودگزارشدهى خستخى توسط شركت كنند

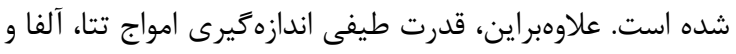
بتا در طول زمان با وظيفه كاهش يافته است. اين نتايج، يافتههاى

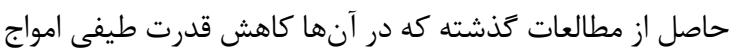
در افزايش خستكى ذهنى كزارش شده است را تأييد مى كند

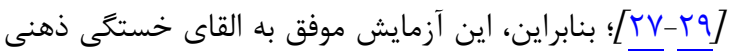
در شركت كنندگان بوده است. همان كونه كه در تغييرات امواج آلفا، بتا و تتا مشاهده

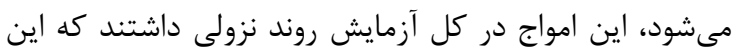

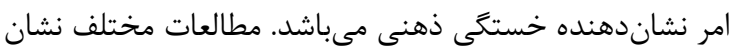
دادهاند كه با افزايش سطح خستخى ذهنى ذهنى، توان نسبى رئى ريتمهاى

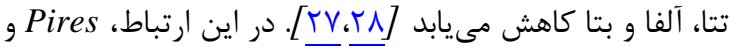

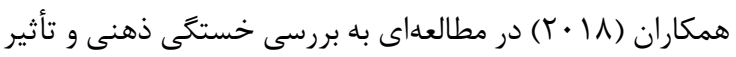

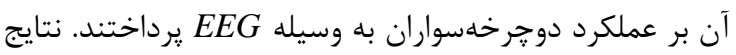

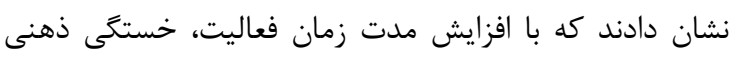

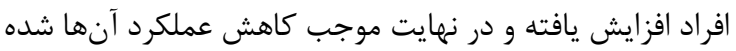

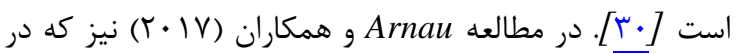

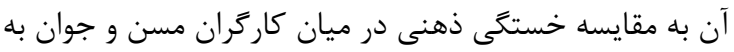

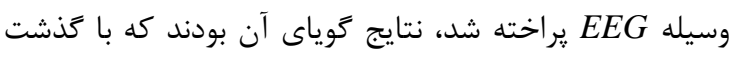
زمان امواج تتا، آلفا و بتا كاهش يافته است. شركت كت كنند به وسيله مقياس خودكزارشدهى اين خستتى رات رات تأييد نمودند

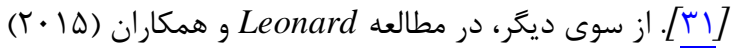

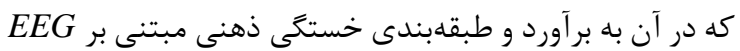

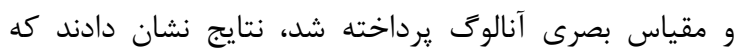
خستكى ذهنى در مقياس بصرى افزايش داشته و عملكرد افراد

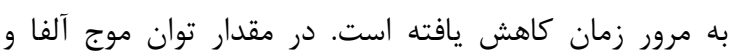

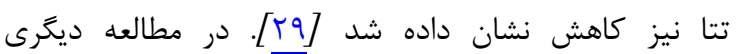
Charbonnier در ايراتورهاى كنترل با استفاده از EEG و مقياس
مرحله اول كه افراد بدون هيج گونه فعاليت ذهنى بودهاند تا مرحله

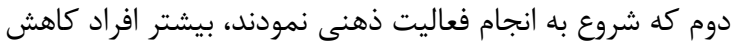

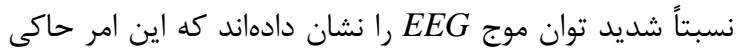

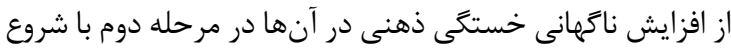

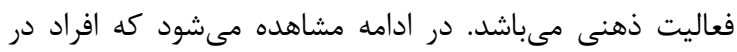

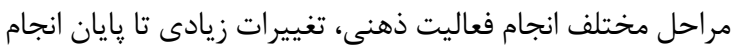

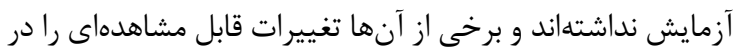
تمامى مراحل آزمايش از خود نشان ندادهاند؛ بهطورى كه كه نمودار

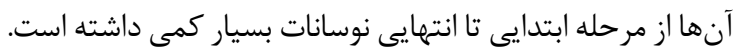

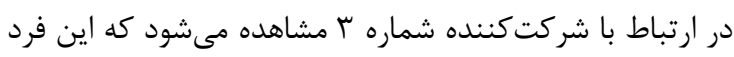
به همان سرعتى كه در مرحله دوم كاهش در فعاليت توان

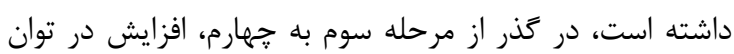

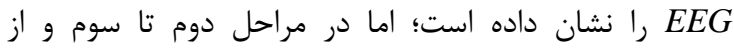

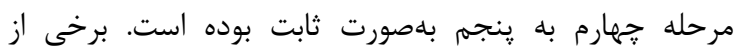

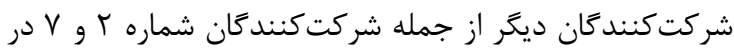

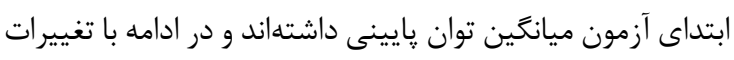

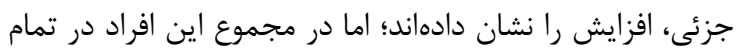
مراحل داراى ميانگين توان پايينى بودهاند.

مطالعه حاضر به بررسى تغييرات توان EEG و شاخصهاى آن در بين كارمندان دانشكده بهداشت در شرايط بدون فعاليت برديت

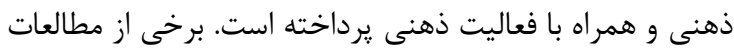

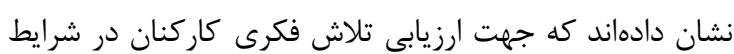

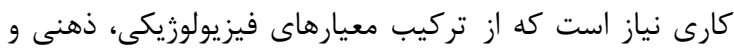

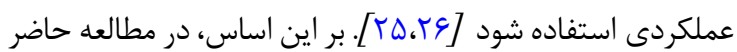
از تركيب EEG، مقياس KSS و انجام وظيفه مطالعه بهعنوان

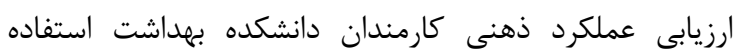

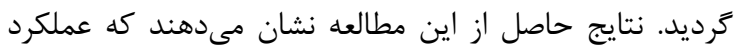

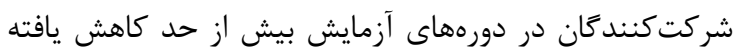


افزايش مىيابد. همجنين، در فعاليت ذهنى محاسبالى (حتى

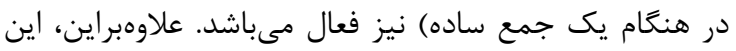
فركانس در برخى از نقاط سر تحت شرايط فكركردن و ونمان

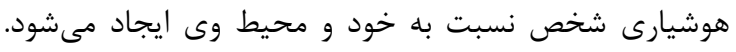

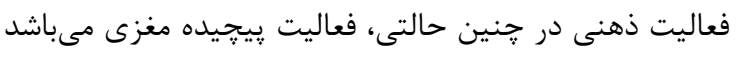

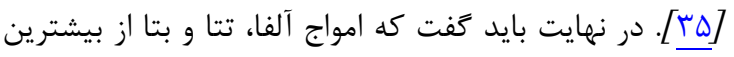

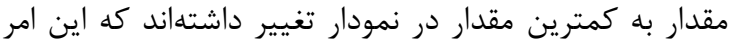

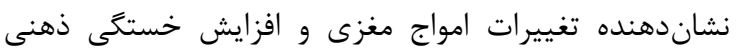
شركت كنند

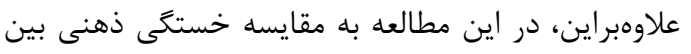

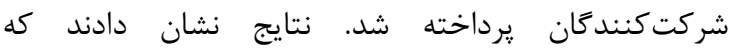
شركتكنند كردهاند؛ اما در افراد مختلف، تفاوتهايى مشاهده شده است؛ رداء

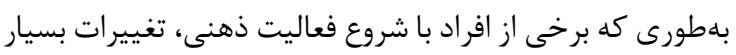

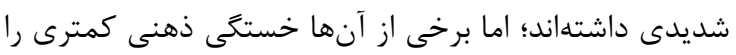

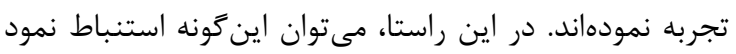

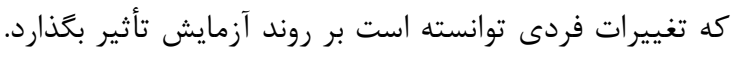

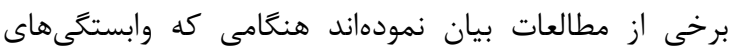

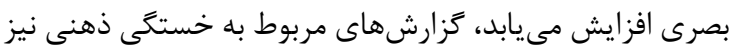

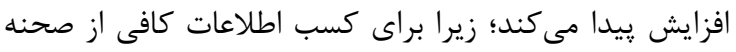

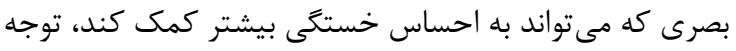

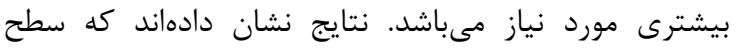
هوشيارى افراد و سطح هيجانى مغز يس از اتمام كار به ميزان بـان

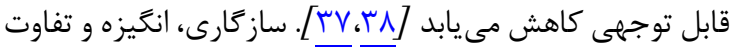
بين فردى متغيرهاى مهمى در بروز خستكى ذهنى ذهنى هستند.

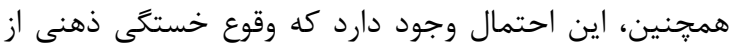

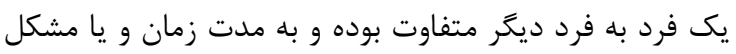

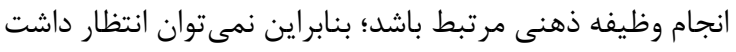

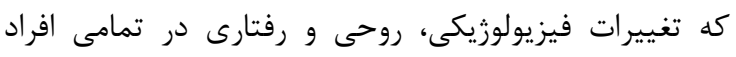

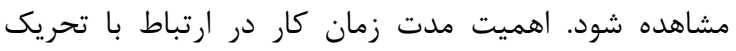
خستكى ذهنى در مطالعه Hagger و همكاران نيز مورد تأكيد

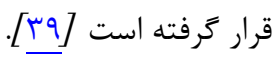

در يزوهش حاضر به بررسى خستخى ذهنى و تأثير آن بر آن

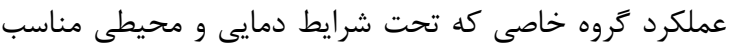

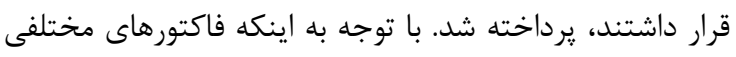

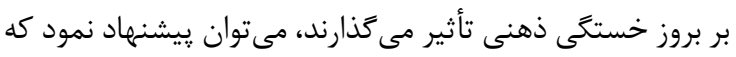

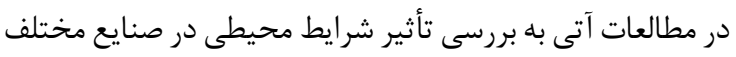

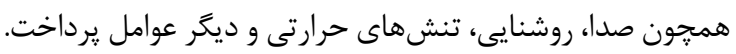

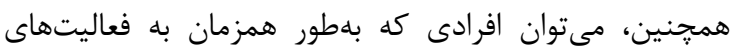

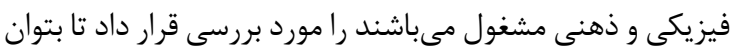

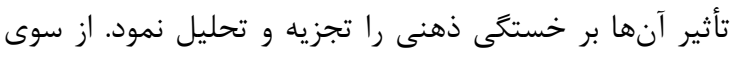

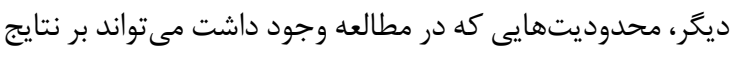

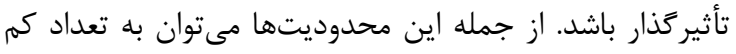

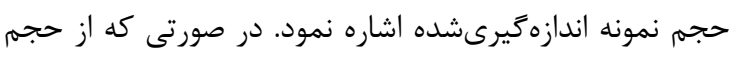

يرداختند. نتايج حاكى از آن بودند كه ايراتورها در حين فعاليت،

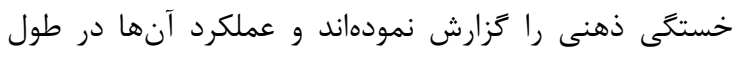
آزمايش كاهش داشته است. در مقدار توان موج آلفا نيز كاهش داهن

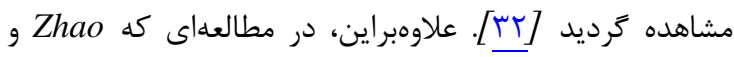

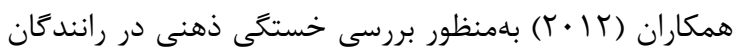

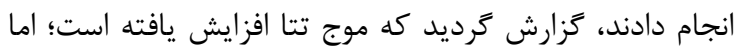

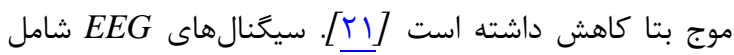

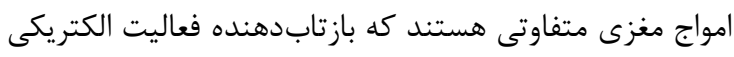

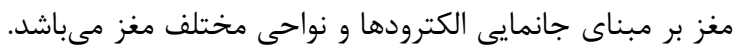

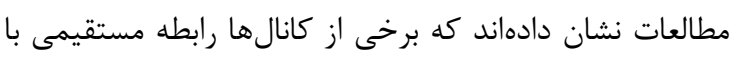
افزايش خستكى ذهنى داشته و برخى ديگر رابطه معكوس دارند.

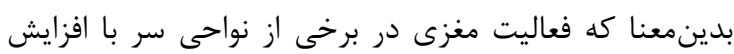

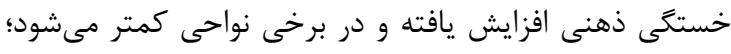

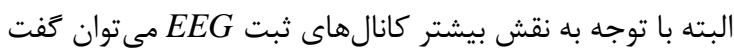

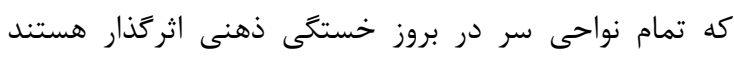

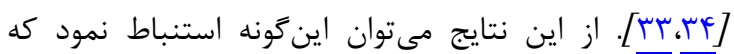
جانمايى الكترودها مىتواند بر تغييرات امواج مغزى تأثير حذاشته و در برخى نواحى كاهش و در نواحى ديكر افزايش را به دنبال داشته باشد. از سوى ديكر، نتايج مطالعه حاضر نشان دادند كه امواج

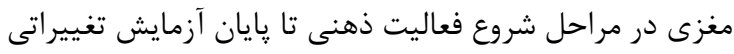

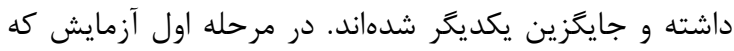

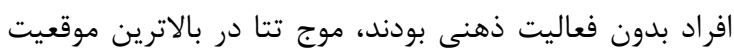

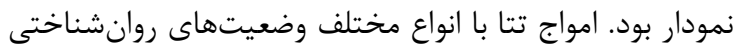

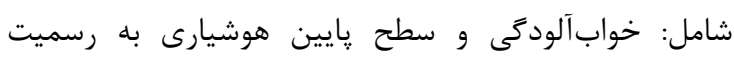

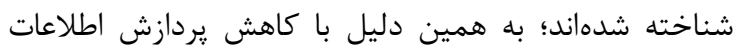

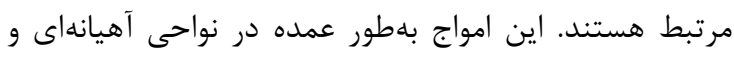

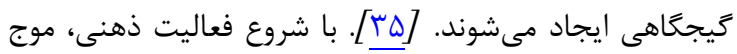

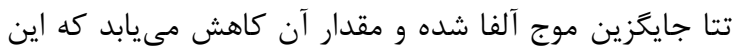

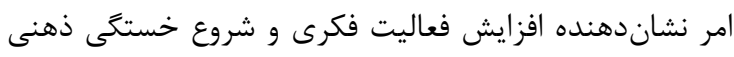

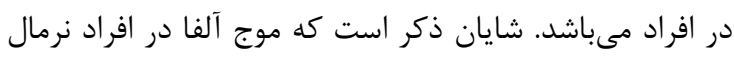

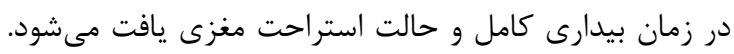

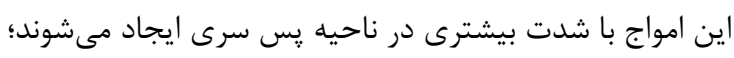

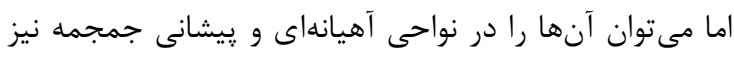

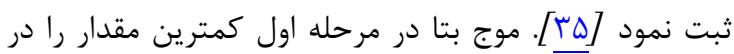

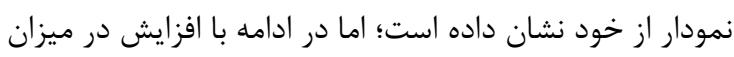

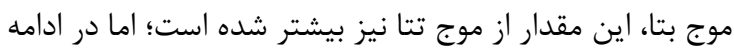

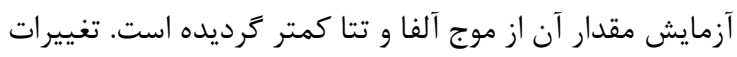

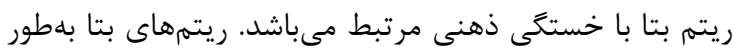

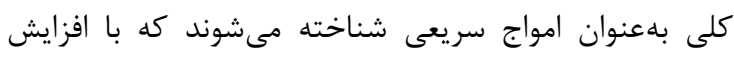

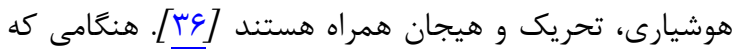

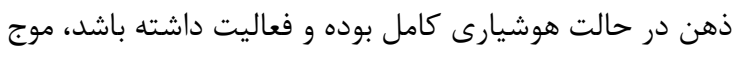

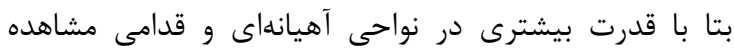

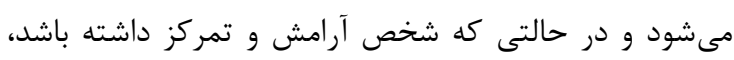


آنها گردد؛ از اين رو بلمنظور سنجش پيامدهاى جبراننايذير

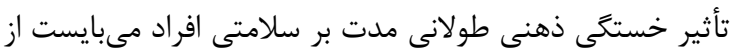

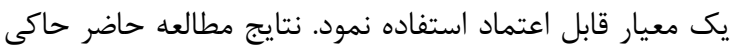

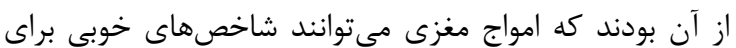
ييشبينى زودهنگام خستخى ذهنى باشند. تشكر و قلر هانى

اين مقاله بركرفته از بخشى از پاياننامه كارشناسى ارشد

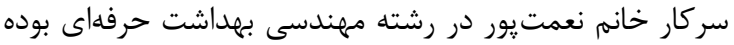

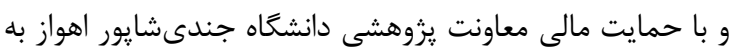

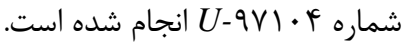

\section{REFERENCES}

1. Lorist MM, Bezdan E, ten Caat M, Span MM, Roerdink JB, Maurits NM. The influence of mental fatigue and motivation on neural network dynamics; an EEG coherence study. Brain Res. 2009;1270:95-106. PMID: 19306850 DOI: 10.1016/j. brainres.2009.03.015

2. Halvani $G H$, Baghianimoghadam MH, Rezaei MH. Fatigue situation in tile industries workers. Iran Occupat Health. 2007;4(3):57-63. [Persian]

3. Philip P, Sagaspe P, Taillard J, Valtat C, Moore N, Akerstedt $T$, et al. Fatigue, sleepiness, and performance in simulated versus real driving conditions. Sleep. 2005;28(12):1511-6. PMID: 16408409

4. Chuckravanen D. Multiple system modelling and analysis of physiological and brain activity and performance at rest and during exercise. Tyne, England: Northumbria University; 2012.

5. van der Linden D. The urge to stop: the cognitive and biological nature of acute mental fatigue. Washington, DC, US: American Psychological Association: 2011. P. 149-64.

6. Faber LG, Maurits NM, Lorist MM. Mental fatigue affects visual selective attention. PloS One. 2012;7(10):e48073. PMID: 23118927 DOI: 10.1371/journal.pone.0048073

7. van der Linden $D$, Eling P. Mental fatigue disturbs local processing more than global processing. Psychol Res. 2006;70(5):395-402. PMID: 15968553 DOI: $10.1007 / \mathrm{s} 00426$ -

\section{5-0228-7}

8. Wright RA, Stewart CC, Barnett BR. Mental fatigue influence on effort-related cardiovascular response: extension across the regulatory (inhibitory)/non-regulatory performance dimension. Int J Psychophysiol. 2008;69(2):127-33. PMID: 18499290 DOI: 10.1016/j.ijpsycho.2008.04.002

9. Anund A, Ahlström C, Kecklund G, Akerstedt T. Rumble strips in centre of the lane and the effect on sleepy drivers. Ind Health. 2011;49(5):549-58. PMID: 21804273

10. Oginska H, Fafrowicz M, Golonka K, Marek T, Mojsa-Kaja $J$, Tucholska K. Chronotype, sleep loss, and diurnal pattern of salivary cortisol in a simulated daylong driving. Chronobiol Int. 2010;27(5):959-74. PMID: 20636209 DOI: 10.3109/ 07420528.2010 .489412

11. Putilov AA, Donskaya OG. Construction and validation of the EEG analogues of the Karolinska sleepiness scale based on the Karolinska drowsiness test. Clin Neurophysiol. 2013;124(7):1346-52. PMID: 23474052 DOI: 10.1016/j. clinph.2013.01.018

12. Kaida K, Takahashi M, Akerstedt T, Nakata A, Otsuka Y, Haratani $T$, et al. Validation of the Karolinska sleepiness scale against performance and EEG variables. Clin Neurophysiol. 2006;117(7):1574-81. PMID: 16679057 DOI: 10.1016/i.clinph.2006.03.011

13. Vecchiato $G$, Astolfi L, De Fallani F, Cincotti F, Mattia D, Salinari $S$, et al. Changes in brain activity during the observation of TV commercials by using EEG, GSR and HR measurements. Brain Topogr. 2010;23(2):165-79. PMID: 20033272 DOI: $10.1007 /$ s10548-009-0127-0
نمونه بزرگترى استفاده شود، مىتوان احتمال داد كه نتايج دقيقترى بهدست خواهد آمد. از ديخر محدوديتهاى اين مطالعه، تعداد كم كانال هاى EEG اندازهخيرىشده بود. در اين ارتباط، با افزايش تعداد كانالها مىتوان به بررسى دقيقتر خستخى ذهنى يرداخت.

\section{نتيجه كيرى}

نتايج مطالعه حاضر نشان دادند كه سطح خستخَى ذهنى در كارمندان دانشكده بهداشت بالا مىباشد. همجنين، مشاهده گرديد كه بين خستخى ذهنى و كاهش دقت، تمركز و هوشيارى افراد ارتباط مثبتى وجود دارد كه مى تواند باعث كاهش عملكرد

14. Chuckravanen D, Rajbhandari S, Bester A. Brain signal analysis using EEG and Entropy to study the effect of physical and mental tasks on cognitive performance. BRAIN. 2015;5(1-4):46-59.

15. Shen KQ, Ong CJ, Li XP, Hui Z, Wilder-Smith EP. A feature selection method for multilevel mental fatigue EEG classification. IEEE Trans Biomed Eng. 2007;54(7):1231-7. PMID: 17605354 DOI: 10.1109/TBME.2007.890733

16. Anund A, Kecklund $G$, Peters B, Forsman A, Lowden A, Akerstedt T. Driver impairment at night and its relation to physiological sleepiness. Scand $J$ Work Environ Health. 2008;34(2):142-50. PMID: 18470435

17. Zhang C, Zheng C, Pei X, Ouyang Y. Power spectrum analysis on the multiparameter electroencephalogram features of physiological mental fatigue. Sheng Wu Yi Xue Gong Cheng Xue Za Zhi. 2009;26(1):162-6. PMID: 19334577

18. Firoozeh $M$, Kavousi A, Hasanzadeh $S$. Evaluation of relationship between occupational exposure to organic solvent and fatigue workers at a paint factory in Saveh city. Iran Occupat Health. 2017;14(2):82-92. [Persian]

19. Ghasemkhani M, Abbasinia M, Mahmoodkhani S, Aghaee H, Asghari $M$. Assessment of fatigue and its relationship with Insomnia Severity Index in shift workers, fixed and rotating, Tehran rolling mills and steel production company. Iran Occupat Health. 2013;10(2):79-86. [Persian]

20. Ghavidel N, Samadi M, Kharmanbiz A, Asadi A, Feyzi A, Ahmadi $R$, et al. Investigation of substance use prevalence and the interrelated factors involved through third-year high school students in Nazarabad city from January 2008 to June 2008. Razi J Med Sci. 2012;19(97):28-36.

21. Zhao C, Zhao M, Liu J, Zheng C. Electroencephalogram and electrocardiograph assessment of mental fatigue in a driving simulator. Accid Anal Prev. 2012;45:83-90. PMID: 22269488 DOI: 10.1016/j.aap.2011.11.019

22. Hsu BW, Wang MJ, Chen CY, Chen F. Effective indices for monitoring mental workload while performing multiple tasks. Percept Mot Skills. 2015;121(1):94-117. PMID: 26226284 DOI: 10.2466/22.PMS.121c12x5

23. Zare $R$, Choobineh $A$, Keshavarzi $S$, Moghateli $S$. Investigation of the relationship of sleep quality, sleepiness and sickness absence. Iran J Ergon. 2016;4(2):1-7. DOI: 10.21859/joe-040230

24. Núñez IMB. EEG artifact detection. Czechia: Czech Technical University in Prague; 2011.

25. Abd-Elfattah HM, Abdelazeim FH, Elshennawy S. Physical and cognitive consequences of fatigue: a review. $J A d v$ Res. 2015;6(3):351-8. PMID: 26257932 DOI: 10.1016/j. jare.2015.01.011

26. Baumeister J, Reinecke $K$, Liesen H, Weiss M. Cortical activity of skilled performance in a complex sports related motor task. Eur J Appl Physiol. 2008;104(4):625-31. PMID. 18607621 DOI: 10.1007/s00421-008-0811-x

27. Fan $X$, Zhou $Q$, Liu Z, Xie F. Electroencephalogram assessment of mental fatigue in visual search. Biomed Mater Eng. 2015;26(Suppl 1):S1455-63. PMID: 26405908 DOI: 10.3233/BME-151444 
28. Craig A, Tran Y, Wijesuriya N, Nguyen H. Regional brain wave activity changes associated with fatigue. Psychophysiology. 2012;49(4):574-82. PMID: 22324302 DOI: 10.1111/j.1469-8986.2011.01329.x

29. Trejo LJ, Kubitz, K, Rosipal R, Kochavi RL, Montgomery LD. EEG-based estimation and classification of mental fatigue. Psychology. 2015;6(5):572. DOI: 10.4236/psych.2015.65055

30. Pires FO, Silva-Júnior FL, Brietzke C, Franco-Alvarenga PE, Pinheiro FA, de Franca NM, et al. Mental fatigue alters cortical activation and psychological responses, impairing performance in a distance-based cycling trial. Front Physiol. 2018;9:227. $\quad$ PMID: $\quad 29615923$ DOI: 10.3389/fphys.2018.00227

31. Arnau S, Möckel T, Rinkenauer $G$, Wascher $E$. The interconnection of mental fatigue and aging: an EEG study. Int J Psychophysiol. 2017;117:17-25. PMID: 28400244 DOI: 10.1016/j.ijpsycho.2017.04.003

32. Charbonnier $S$, Roy RN, Bonnet $S$, Campagne A. EEG index for control operators' mental fatigue monitoring using interactions between brain regions. Expert Syst Appl. 2016;52:91-8. DOI: 10.1016/j.eswa.2016.01.013

33. Hsu BW, Wang MJ. Evaluating the effectiveness of using electroencephalogram power indices to measure visual fatigue. Percept Mot Skills. 2013;116(1):235-52. PMID: 23829150 DOI: 10.2466/29.15.24.PMS.116.1.235-252

34. Rosipal R, Trejo LJ, Zaidel E. Atomic decomposition of EEG for mapping cortical activation. Prague: Tensor Methods for Machine Learning Workshop; 2013.

35. Lal SK, Craig A. Driver fatigue: electroencephalography and psychological assessment. Psychophysiology. 2002;39(3): 313-21. PMID: 12212650 DOI: 10.1017.SO048577201393095

36. Eoh HJ, Chung MK, Kim SH. Electroencephalographic study of drowsiness in simulated driving with sleep deprivation. Int $J$ Ind Ergon. 2005;35(4):307-20. DOI: 10.1016/i.ergon.2004. $\underline{09.006}$

37. Davids K, Williams JG, Williams AM. Visual perception and action in sport. Abingdon: Routledge; 2005.

38. Williams AM. Perceptual skill in soccer: Implications for talent identification and development. J Sports Sci. 2000;18(9):73750. PMID: 11043899 DOI: 10.1080/02640410050120113

39. Hagger MS, Chatzisarantis NL, Alberts $H$, Anggono CO, Batailler $C$, Birt AR, et al. A multilab preregistered replication of the ego-depletion effect. Perspect Psychol Sci. 2016; 11(4):546-73. PMID: 27474142 DOI: $10.1177 / 17456916$ $\underline{16652873}$ 